Available online at http://jurnal.stmikroyal.ac.id/index.php/jurteksi

\title{
ILUSTRASI 3D HARDWARE PADA KOMPUTER UNTUK MATAKULIAH PRAKTIKUM PENGANTAR TERKNOLOGI INFORMASI
}

\author{
Ketut Gus Oka Ciptahadi \\ Prodi Sistem Informasi, Institut Teknologi dan Bisnis STIKOM Bali \\ email: okaciptahadi@stikom-bali.ac.id
}

\begin{abstract}
Practicum Introduction to Information Technology is a general course that is always present at every IT campus in Indonesia. To give an introduction to hard ware to students, each lecturer always requires a long time, because they have to open (CPU) the Central Processing Unit and release other components to be explained by students. Inefficient time in opening and releasing computer hardware components when the course is taking place is the main problem that will be solved by researchers in this study. Plus the computer components that will be explained are quite small, making students unable to see it clearly when in the teaching and learning process. The offered solution, utilizing a technology based on 3D animation. Where this 3D animation technology will provide a more realistic appearance. As in the study entitled SINDO JOURNALIST 3D FILM ANIMATION in the journal Art Design and Culture volume 2. No. 1 March 2017, which researchers have reviewed, also explained that the use of 3D design technology can produce vivid and real visuals that are close to their original form [1]. The method in developing 3D animation in this study uses the Reseach and Development (R\&D) Method. Conclusions from this study, researchers have succeeded in making a 3D animation-based information media about the introduction of computer hardware for the Introduction to Information Technology Practicum, with the process of animation results that have been tested using blackbox test.
\end{abstract}

Keywords: animation; hardware; research and development

\begin{abstract}
Abstrak: Mata kuliah praktikum Pengantar Teknologi Informasi adalah matakuliah umum yang selalu terdapat pada setiap kampus IT di Indonesia. Untuk memberikan pengenalan hardware kepada peserta didik, setiap dosen selalu membutuhkan waktu yang cukup lama, dikarenakan harus membuka (CPU) Central Processing Unit dan melepaskan komponen lainnya agar dapat dijelaskan oleh peserta didik. Tidak efisiennya waktu dalam membuka dan melepaskan komponen hardware komputer ketika matakuliah berlangsung menjadi permasalahan utama yang akan diselesaikan peneliti dalam penelitian kali ini. Ditambah lagi komponen komputer yang akan dijelaskan cukup kecil, membuat peserta didik tidak dapat melihatnya dengan jelas ketika dalam proses belajar mengajar. Solusi yang ditawarkan, memanfaatkan sebuah teknologi berbasis 3D animasi. Dimana teknologi 3D animasi ini akan memberikan tampilan yang lebih realistis. Metode didalam pengembangan animasi 3D pada penelitian ini menggunakan Metode Reseach and Development (R\&D). Simpulan dari penelitian ini, peneliti sudah berhasil membuat sebuah media informasi berbasis animasi 3D tentang pengenalan hardware komputer untuk matakuliah Praktikum Pengantar Teknologi Informasi, dengan proses hasil animasi yang sudah diuji dengan menggunakan blackbox testing.
\end{abstract}

Kata kunci: animasi; hardware; reseach and development. 
Available online at http://jurnal.stmikroyal.ac.id/index.php/jurteksi

\section{PENDAHULUAN}

Mata kuliah praktikum Pengantar Teknologi Informasi adalah matakuliah umum yang selalu terdapat pada setiap kampus IT di Indonesia. Salah satu pembahasan yang selalu muncul pada matakuliah tersebut, terkait dengan pengenalan hardware komputer. Untuk memberikan pengenalan hardware kepada peserta didik, setiap dosen selalu membutuhkan waktu yang cukup lama, dikarenakan harus membuka CPU dan melepaskan komponen lainnya agar dapat dijelaskan oleh peserta didik.

Tidak efisiennya waktu yang diperlukan dalam membuka dan melepaskan komponen hardware komputer pada saat matakuliah berlangsung menjadi permasalahan utama yang akan diselesaikan dalam penelitian kali ini. Ditambah lagi komponen komputer yang akan dijelaskan cukup kecil yang membuat peserta didik tidak bisa melihatnya dengan baik. Ketika dalam proses belajar mengajar. Solusi yang ditawarkan pada penelitian ini adalah memanfaatkan sebuah teknologi berbasis 3D animasi. Dimana teknologi 3D animasi ini akan memberikan tampilan yang lebih realistis. Seperti pada penelitian sebelumnya menjelaskan bahwa penggunaan Teknologi 3D desain dapat menghasilkan visual yang hidup dan nyata mendekati wujud aslinya [1]. Solusi dari penelitian kali ini akan bertujuan untuk memudahkan Tenaga pendidik atau dosen ketika melakukan proses mengajar pada matakuliah Praktikum Pengantar Teknologi Informasi. Animasi 3D yang dirancang peneliti akan menampilkan setiap komponen perangkat keras komputer secara detail lengkap dengan fungsi dan kegunaannya.

Proses produksinya juga meng- gunakan rendering beresolusi HD. Dengan memanfaatkan fasilitas rendering mental Ray yang terdapat pada software autodesk maya. Metode didalam pengembangan animasi 3D pada penelitian ini menggunakan reseach and development $(R \& D)$. dan pada tahap terakhir peneliti juga akan melakukan proses pengujian blackbox testing terkait animasi yang dirancang.

\section{Kajian Literatur Review}

Berikut peneliti jelaskan terkait kajian terdahulu, judul penelitian design of $3 D$ animation special effects in animation $3 D$ modeling teaching based on qfd theory [4]. Penelitian ini menghasilkan sebuah media pembelajaran cara pembuatan modeling 3D. Perbandingan pene-litian yang sekarang, yaitu memanfaatkan bidang 3D sebagai media pengajaran praktikum PTI. research on $3 D$ painting in virtual reality to improve students' motivation of $3 D$ animation learning, [3]. Penelitian tersebut membuat perangkat pembelajaran guna memotivasi siswa dalam hal pewarnaan 3D. Perbandingan sekarang, membuat media pembelajaran yang berbasis 3D namun praktis dan ekonomis dan dari segi pembiayaan hardware dan fasilitas ruangan. 3D animation: don't drink and drive, [5]. Peneliti tersebut membuat sebuah iklan 3D bahaya mengemudi sambil minum. Perbandingan dengan peneliti sekarang, menghasilkan media pembelajaran animasi 3D serta menambahkan penggunaan effect typografi animation agar animasi terlihat lebih dinamis. 3D characters modeling and animation, [6]. Penelitian ini dapat menghasilkan karakter 3D menggunakan 3DS MAX, dalam proses texturing masih belum realistis. Perbandingan penelitian sekarang, membuat modeling properti desain yang lebih halus menggabungkan software adobe pho- 
Available online at http://jurnal.stmikroyal.ac.id/index.php/jurteksi

toshop untuk pembuatan texture. further the future: the exploratory study in $3 D$ animation marketing trend and industry in thailand, [7]. Penelitian menghasilkan animasi untuk dipergunakan sebagai media marketing. Perbandingan penelitian sekarang, menambahkan script pada animasi untuk membuat alur cerita animasi menjadi terkonsep. 3D character animation: a brief review, [8]. Penelitian menjelaskan bagaimana cara membuat animasi menggunakan sekeleton atau skning. Perbandingan penelitian sekarang, membuat modeling lebih detail. dengan mengurangi eror pada proses skinning. pengenalan wisata pancer door dengan animasi 3 dimensi, [9]. Penelitian ini menghasilkan sebuah media promosi obyek wisata. Perbandingan dengan sekarang, membuat animasi dengan berkonsep media pembelajaran. Perancangan Film Animasi Pendek 2D Sebagai Media Kampanye Penanganan Anxiety Disorder, [10]. Menghasilkan satu animasi dengan konsep calm and education. Perbandingan dengan sekarang, membuat animasi dengan pembelajaran linier.

\section{METODE}

\section{Metode Pengembangan}

Dalam pengembangan animasi, penelitian menggunakan metode $\mathrm{R} \& \mathrm{D}$ (Research And Development). Metode penelitian dan pengembangan (Research And Development) atau disingkat dengan R\&D merupakan metode penelitian yang digunakan untuk menghasilkan sebuah produk tertentu, dan menguji keefektifan produk tersebut [2].

\section{Alur Penelitian \\ Membagi metode penelitian men- jadi empat tahapan utama sebagai berikut}

adalah Tahap Studi Pendahuluan, Tahap Pengembangan, Tahap Evaluasi, Tahap Dokumentasi. Beikut akan dijelaskan pada gambar berikut.

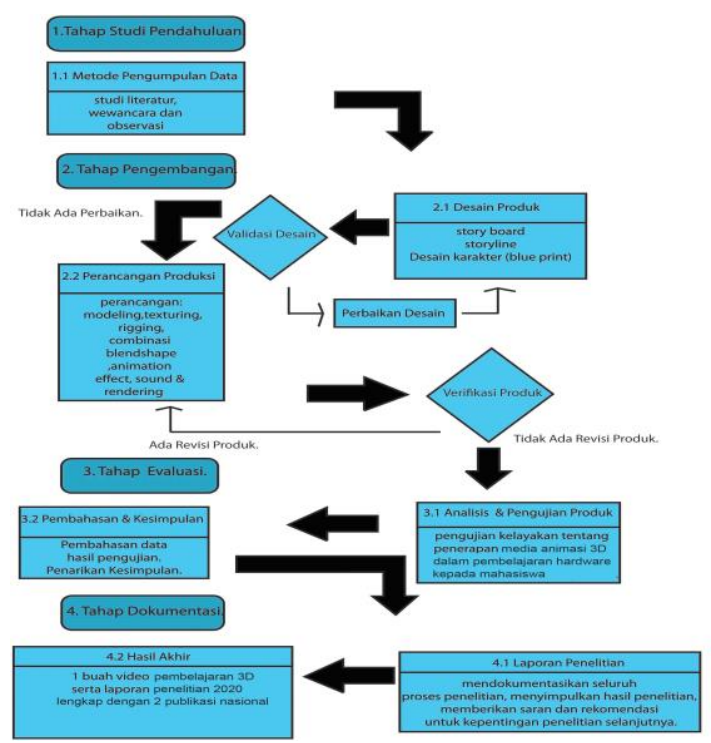

Gambar 1. Alur penelitian

\section{Lokasi Penelitian}

Memfokuskan pada 1 lokasi penelitian yaitu bertempat di kampus ITB STIKOM Bali Jimbaran, yang akan dijadikan sebagai tempat untuk melakukan proses impelementasi atau publikasi pertama dari hasil animasi 3D yang dibuat.

\section{Pengujian Produk}

Dalam proses pengujian animasi 3D, menggunakan pengujian blackbox testing. Yang bertujuan untuk mendapatkan penilian hasil animasi dari segi animasi kamera, animasi modeling 3D detail dan render video. Pengujian tersebut diarahkan kepada kepala kooridnator Matakuliah Pengantar Teknologi Informasi, I Putu Ramayasa. Pengujian pada black box testing tidak terlalu memperhatikan struktur internal (source code) dari produk atau sistem, tetapi lebih kepada menemukan kesala- 
han pada sebuah produk atau sistem. Pengujian black box testing. Dapat diartikan sebagai pengujian alpha. Pengujian alpha dilakukan terhadap aplikasi atau sistem untuk memastikan bahwa aplikasi atau system sudah dapat berjalan dengan benar sesuai dengan kebutuhan dan tujuan yang diharapkan.

\section{HASIL DAN PEMBAHASAN}

\section{Konsep Desain}

Pada tahapan ini, mengkonsepkan media informasi pengenalan hardware dengan menyusun pengenalan model hardware pada bagian yang paling kecil dulu baru memperlihatkan bagian modeling yang berukuran lebih besar. Serta ditambah dengan deskripsi berupa dubbing yang akan menjelaskan setiap bagian modeling hardware. Konsep gambaran kasar dan deskirpsi akan dijadikan satu dlam bentuk desain storyboard.

Tabel 2. Cuplikan 1 scene Storyboard

\begin{tabular}{|c|l|}
\hline \multicolumn{1}{|c|}{} & Scene:2 \\
& Durasi: \\
& 10.00 detik \\
& Deskripsi: \\
& Menjelaskan \\
& sebuah \\
\hline \multicolumn{1}{|c|}{ Info: Monitor adalah } & monitor. \\
perangkat keras yang & Backsound: \\
digunakan sebagai alat & Technology \\
output data secara grafis & beat song. \\
pada sebuah CPU, mon- & Shoot: LS \\
\hline \multicolumn{2}{|l}{} \\
\hline
\end{tabular}

\section{Validasi Desain}

Keseluruhan desain storyboard, akan dilakukan proses penilaian. Penilaian dilakukan oleh 2 pakar ahli yaitu koorinator dosen pengampu matakuliah Praktikum Teknologi Infor- masi pada kampus ITB STIKOM Bali dan 1 pakar animasi dari Multimedia Art Digital Bali.Tabel 3.Form Validasi Desain

\begin{tabular}{lll}
\hline \multicolumn{3}{l}{ Form Validasi Desain } \\
\hline Nama & Hasil & Saran \\
\hline Putu Rama- & Informasi & Format \\
yasa (ITB & dan gambar & animasi \\
STIKOM & sudah baik. & $\begin{array}{l}\text { mohon } \\
\text { dibuat 2K. }\end{array}$ \\
BALI) & & \\
\hline Adi Febri- & Desain su- & Setiap \\
ana (Multi- & dah tekon- & pergerakan \\
media Art & sep dengan & ainimasi \\
Digital Bali) & baik. & $\begin{array}{l}\text { dibuat } \\
\text { dengan fps } \\
\end{array}$ \\
& & minimal 60. \\
\hline
\end{tabular}

\section{Produksi Animasi}

Dilanjutan dengan proses pembuatan animasi 3D. Animasi dibuat menggunakan software autodesk maya. Masukan yang didapat dari proses validasi desain akan diimplementasikan pada tahap produksi animasi. Pada tahap produksi menggunakan setingan graph editor untuk memperhalus gerakan animasi. Seperti dengan sebuah curve untuk mengedit pewarnaan. Graph editor juga berfungsi menentukan percepatan dan perlambatan sebuah asegan animasi.

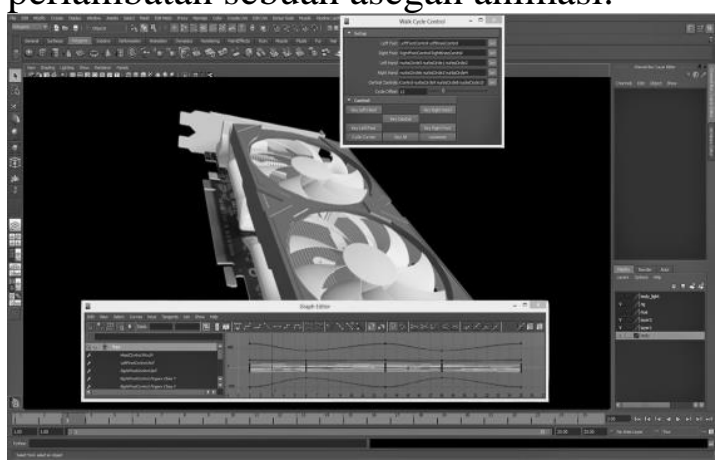

Gambar 2.Pembuatan Produksi Animasi

\section{Hasil Tampilan Animasi}

Animasi yang diproduksi sudah selesai oleh peneliti dirender dengan format vid- 
Available online at http://jurnal.stmikroyal.ac.id/index.php/jurteksi

eo $2048 \times 1080$ atau $2 \mathrm{~K}$. dditambah menggunakan FPS berjumlah 60. Berikut hasil screenshot dari ilustrasi 3D hardware untuk matakuliah Pengantar Tekologi Informasi.

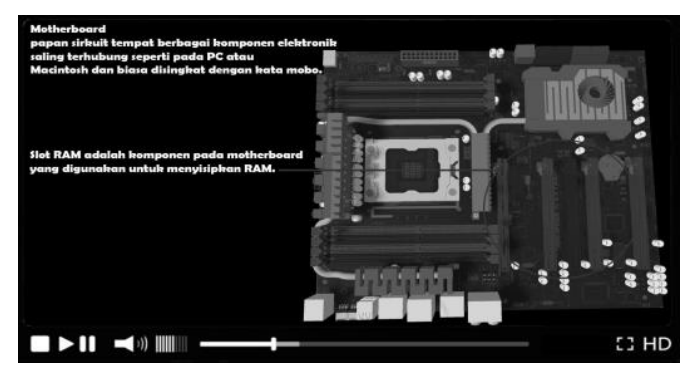

Gambar 3. Hasil Animasi Motherboard

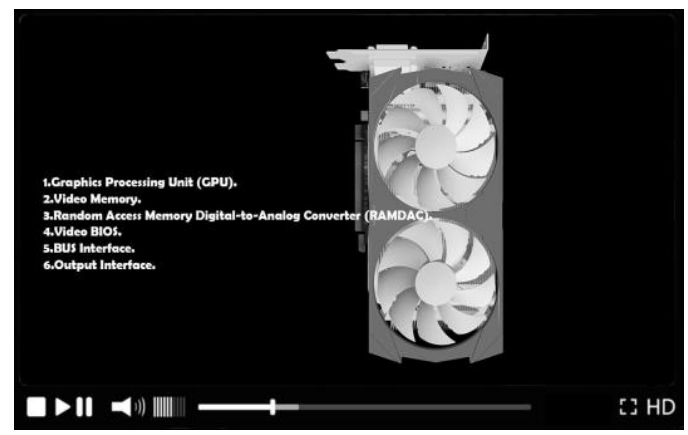

Gambar 4. Hasil Animasi VGA

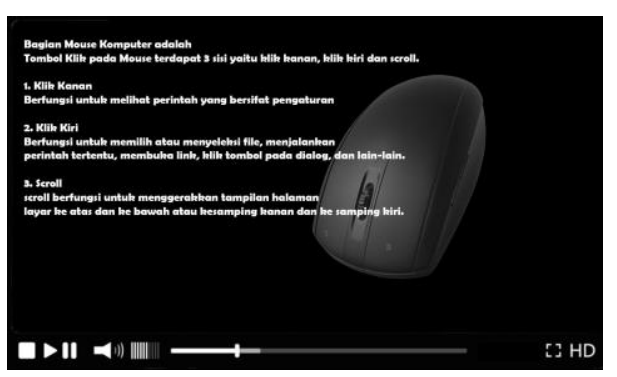

Gambar 5. Hasil Animasi Mouse

\section{Tahap Testing}

Tahap Tes (Testing) Pada tahap tes ini dilakukan pengujian produk animasi dengan menggunakan blackbox testing untuk menemukan kesalahan atau terjadi eror pada produk animasi. Pengujian ini dilakukan dengan mengujikan setiap pergerakan animasi dan kesesuain konsep desain yang terdapat pada storyboard dengan hasil akhir dari produk animasi

yang dirancang peneliti. Yang bertujuan dari proses testing ini adalah untuk memastikan apakah proses-proses yang dilakukan menghasilkan output yang sesuai dengan rancangan.

\begin{tabular}{|c|c|c|c|}
\hline \multicolumn{4}{|c|}{ Hasil Uji Animasi Kamera } \\
\hline $\begin{array}{l}\text { Aktifi- } \\
\text { tas } \\
\text { pen- } \\
\text { gujian }\end{array}$ & $\begin{array}{l}\text { Realisasi } \\
\text { harapan }\end{array}$ & $\begin{array}{l}\text { Hasil } \\
\text { pen- } \\
\text { gujian }\end{array}$ & $\begin{array}{l}\text { Hasil } \\
\text { kese- } \\
\text { luruhan } \\
\text { proses }\end{array}$ \\
\hline $\begin{array}{l}\text { Test } \\
\text { camera } \\
1 \text { (long } \\
\text { shot) } \\
\text { Test } \\
\text { camera } \\
2 \\
\text { Close } \\
\text { up) }\end{array}$ & $\begin{array}{l}\text { Dapat } \\
\text { menam- } \\
\text { pilkan } \\
\text { kese- } \\
\text { luruhan } \\
\text { dan detail } \\
\text { objek }\end{array}$ & $\begin{array}{l}\text { Ani- } \\
\text { masi } \\
\text { ber- } \\
\text { hasil } \\
\text { Ani- } \\
\text { masi } \\
\text { ber- } \\
\text { hasil }\end{array}$ & $\begin{array}{l}\text { Diterim } \\
\mathrm{a}\end{array}$ \\
\hline
\end{tabular}

Hasil Uji Modeling Animasi

\begin{tabular}{|c|c|c|c|}
\hline $\begin{array}{l}\text { Aktifi- } \\
\text { tas } \\
\text { pen- } \\
\text { gujian }\end{array}$ & $\begin{array}{l}\text { Realisasi } \\
\text { harapan }\end{array}$ & $\begin{array}{l}\text { Hasil } \\
\text { pen- } \\
\text { gujian }\end{array}$ & $\begin{array}{l}\text { Hasil } \\
\text { kese- } \\
\text { luruhan } \\
\text { proses }\end{array}$ \\
\hline $\begin{array}{l}\text { Rotasi } \\
\text { perge- } \\
\text { rakan } \\
\text { objek } \\
\text { (verti- } \\
\text { cal dan } \\
\text { hori- } \\
\text { zontal) }\end{array}$ & $\begin{array}{l}\text { Objek- } \\
\text { bergerak } \\
\text { perlahan } \\
\text { berputar }\end{array}$ & $\begin{array}{l}\text { Ani- } \\
\text { masi } \\
\text { ber- } \\
\text { hasil } \\
\text { Ani- } \\
\text { masi } \\
\text { ber- } \\
\text { hasil }\end{array}$ & $\begin{array}{l}\text { Diterim } \\
\mathrm{a}\end{array}$ \\
\hline \multicolumn{4}{|c|}{ Hasil Uji Render Video } \\
\hline $\begin{array}{l}\text { Aktifi- } \\
\text { tas } \\
\text { pen- } \\
\text { gujian }\end{array}$ & $\begin{array}{l}\text { Realisasi } \\
\text { harapan }\end{array}$ & $\begin{array}{l}\text { Hasil } \\
\text { pen- } \\
\text { gujian }\end{array}$ & $\begin{array}{l}\text { Hasil } \\
\text { kese- } \\
\text { luruhan } \\
\text { proses }\end{array}$ \\
\hline $\begin{array}{l}\text { Cek fps } \\
\text { animasi } \\
\text { Cek } \\
\text { ukuran } \\
\text { video }\end{array}$ & $\begin{array}{l}\text { Sesuai } \\
\text { dengan } \\
\text { masukan } \\
\text { tim validasi } \\
\text { desain }\end{array}$ & $\begin{array}{l}\text { Sesuai } \\
\text { sesuai }\end{array}$ & Diterim \\
\hline
\end{tabular}


Available online at http://jurnal.stmikroyal.ac.id/index.php/jurteksi

\section{SIMPULAN}

Hasil yang didapat dari penelitian ini adalah, sudah dapat membuat sebuah media informasi berbasis animasi tiga dimensi yang dapat digunakan sebagai salah media pengenalan hardware komputer untuk matakuliah Praktikum Pengantar Teknologi Informasi. Dari pengujian testing yang sudah dilakukan menunjukan bahwa tingkat keberhasilan dalam hasil uji animasi kamera, modeling animasi dan uji render video sudah dalam kategori baik. Kooridnator dari matakuliah Praktikum Pengantar Teknologi Informasi dan Animator dari Multimedia Art Digtal menjadi responden yang melakukan pengujian tersebut. Tidak terdapat kesalahan atau kegagalan dalam hal uji produk animasi. Hasil ini menunjukan bahwa dalam penelitian ini mendapatkan output yang sesuai dengan yang diharapkan

\section{DAFTAR PUSTAKA}

[1] Y. Mariana, "Film Animasi 3D Jurnalis Sindo," Palembang Politek. PalComTech, vol. 2, no. 1, pp. 1826, 2017.

[2] Sugiyono, Metode Penelitian Kuantitatif, Kualitatif, dan $R \& D$. Bandung: Alfabeta, 2013.

[3] L. H. Ho, H. Sun, and T. H. Tsai, "Research on 3D painting in virtual reality to improve students' motivation of 3D animation learning," Sustain., vol. 11, no. 6, pp. 1-17, 2019, doi: 10.3390/su11061605.

[4] Q. Wang, "Design of 3D animation special effects in animation 3D modeling teaching based on QFD theory," Int. J. Emerg. Technol. Learn., vol. 12, no. 7, pp. 90-100,
2017, doi: 10.3991/ijet.v12i07.7218.

[5] I. Ahmed and S. Janghel, "3D Animation: Don't Drink and Drive," Int. J. u- e-Service, Sci. Technol., vol. 8, no. 1, pp. 415-426, 2015, doi: 10.14257/ijunesst.2015.8.1.36.

[6] N. Sad, "3D Characters Modeling and Animation," vol. 4, no. 2, pp. 117-122, 2012.

[7] P. Mongkolprasit and P. Arunrangsiwed, "Further the Future: The Exploratory Study in 3D Animation Marketing Trend and Industry in Thailand," Int. J. Soc. Behav. Educ. Econ. Bus. Ind. Eng., vol. 10, no. 3, pp. 1013-1020, 2016.

[8] H. Song, S. Heo, J. Kang, and S. Lee, "3D Character Animation: A Brief Review," J. Int. Soc. Simul. Surg., vol. 2, no. 2, pp. 52-57, 2015, doi: 10.18204/jissis.2015.2.2.052.

[9] F. Cahyo Hakim and L. Yulianto, "Pengenalan Wisata Pancer Door Dengan Animasi 3 Dimensi," Dialogue A J. Mormon Thought, vol. 48, no. 1, pp. 147-152,188, 2015, [Online]. Available: http://search.proquest.com/docview/ 1781644205 ?accountid $=6802 \% 5 \mathrm{Cnh}$ ttp://snurimo.hosted.exlibrisgroup.co m/openurl/82SNU/SNU_SERVICES _PAGE??url_ver=Z39.88-

2004\&rft_val_fmt=info:ofi/fmt:kev: mtx:journal\&genre $=$ unknown\&sid= ProQ:ProQ\%3Areligion\&atitle=Spri ng+Hi.

[10] G. P. P. A. Yasa, K. A. S. Narpaduhita, and D. G. Purwita, "Perancangan Film Animasi Pendek 2D Sebagai Media Kampanye Penanganan Anxiety Disorder," $J$. Bhs. Rupa, vol. 2, no. 2, pp. 146152, 2019, doi: 10.31598/bahasarupa.v2i2.368. 